\title{
The origin of ancient pottery production
}

\begin{abstract}
The origin of pottery production involves two interconnected processes: the emergence of vessel shapes and pottery technology. To clarify the nature of the first process we need to identify prototypes for the shapes of clay vessels and to determine the functions of the first clay vessels. The study of pottery technology involves the earliest plastic raw materials, composition of pottery pastes and vessels' firing regimes. The research is based on archaeological ceramics from the Near East and Anatolia of 9-8 millennia ago and from the Japan and the Far East of Russia 13-11 millennia ago. A range of ethnographic data was also used. The origin of pottery production (including shapes and technology of vessels) was a result of two main factors - adaptive processes of the tribes to local natural and economical situation and human natural ability to imitation. That is why the origin of pottery production was a polycentric process. It had appeared a lot of times in various regions of the Earth as long as its all-round distribution closed the beginnings of the process.
\end{abstract}

Keywords: origin of ceramics, shape of vessel, raw material, pottery paste
Volume 3 Issue 2 - 2018

\author{
Yuri B Tsetlin \\ History of Ceramics Laboratory, Russian Academy of Sciences, \\ Russia
}

Correspondence: Yuri B Tsetlin, History of Ceramics Laboratory, Russian Academy of Sciences, Russia, Email yu.tsetlin@mail.ru

Received: February 28, 2018| Published: March 20, 2018

\section{Introduction}

Science has long been seeking the answer to the question about the origins of pottery production. That question is indivisibly linked to the question about when and how humans learned to use clay and clay-like materials for domestic and other purposes.

\section{Traditional notions about the origins of pottery production}

Mythological data can be divided into two subgroups:

a. Earliest data on clay use

b. Earliest data on clay vessels.

At first it should also be stated that according the Holy Bible text "And the Lord God formed man of the dust of the ground and breathed into his nostrils the breath of life; and man became a living soul". ${ }^{1}$ In Folklore in the Old Testament JG Frazer lists 33 myths that tell about the creation of the first humans from clay. ${ }^{2}$ We can find these stories in Jewish, Babylonian, Greek and Egyptian lore, whereas ethnographic data shows that similar stories can be found in Australia, New Zealand, Polynesia, Melanesia, Micronesia, Burma, Ceylon, India, the Pacific islands, Sumatra and the Philippines. The Mari people as well as African tribes and tribes in North and South America (from Alaska to Paraguay) also have such myths. Here we should note several common traits: in all of the cases the first humans were created from clay or silt, in all of the cases the creator was a deity and in none of the cases an ordinary human or a priest. Consequently, pottery-making skills initially came from the gods and are of especial significance.

Among these stories we can find especially detailed and interesting ones.

1. The Babylonian priest Berossus told that the gods had created humans from a mixture of earth and divine blood. Similarly, Prometheus was believed to have made humans from clay and some components of the human body. In the 2 nd century AD a Greek traveler claimed to have seen those mounds of clay which had a strong smell of human flesh.

2. Tiki, the Maori god, took some red clay from a river bank and mixed it with his own blood to make an exact copy of himself, into which he breathed life.

3. The first man on Bowditch Island in Polynesia was created from stone. Then that first man created a woman: from earth he made a woman's figurine, then took one of his left ribs and put it into the figurine which then came alive. It is interesting that in this version the first human was made of stone and the second one of clay.

4. In the Palau islands there is a legend that the first humans were made of clay mixed with the blood of different animals and the nature of each person depended on the species of animal. Thus, the people who were made of clay and rat blood were thieves, those made of clay and snake blood were cowards and those made of clay and rooster blood were courageous.

5. The Dayaks (Borneo Island) believed that the first man was created from moist earth and that red resin from a tree was poured into his veins. The man was named Tanah-Kumpok: "the earthformed".

6. Sea Dayaks believed that the god Salampandai created humans from clay using a special hammer to shape it on an anvil. This may remind us of the vessel-beating technique.

7. A legend that is less archaic in content tells that the Egyptian god Khnum, father of the gods, made humans from clay on a potter's wheel.

The above stories are important not only because they tell how 
the gods made humans from clay, but also because they mention certain "technological" details which we already know from studies of ancient pottery. Other myths tell about the discovery of potterymaking itself, i.e. the art of making clay vessels. The Ukamba tribe in East Africa have a curious and very detailed legend: "Those earliest people of long ago who came up out of a territory were given all sorts of food, but they had to eat it raw; it was not cooked. One day a woman set out from the village and went to the river. She went to fetch water from the river in some rolled-up leaves. At the shore she found a peculiar-looking piece of rock, hollow in the middle. She filled it with water and carried it home, where she put it on her hearth. When she prepared the food for her family in the evening she put some of the maize and bean mush into the hollow stone and boiled it and, lo and behold, it tasted wonderful and much better than raw food.

Next morning a neighbor dropped in, saw the hollow stone, admired it and asked whether the woman had another one like it to give to her. "No," said the first woman, "I found it near the river and there was just one." "Let us go there and look for another one!" So the two women started off and looked around. There was no other stone like it, but there was fat and slippery clay and they took some of it, mixed it with water and tried to imitate the shape of the hollow stone. For five days they tried and finally they made little things which they called clay vessels. They burned them in a fire and they became hard and firm as stone. At home they put them on the fireplace and invited all the rest of the women: "Come and see! We have prepared this earth and we are able to boil water in it which does not come out on the fireplace." And they also cooked mush in the vessels and it tasted wonderful! The other women tried to imitate their handicraft, but they did not succeed and whoever wanted a nyun'gu or clay pot had to order it from the two women, who were paid for it in beautiful blue beads.

And they called all the men and there was a big celebration to commemorate the invention of the clay vessels. The women's husbands especially invited the holy old men who spit in the women's hands to bless them. "Pt, pt, pt" made the old men and they said: "You have become very clever. You made the clay vessels!" And they advised the women never to allow a man to watch them while making clay vessels; otherwise they would lose their skill. They abided by this faithfully. That is how mankind learnt to make clay vessels and our people have been blessed with them ever since.'Ukrainian potters in the Polessye region have a legend that it was King Solomon who taught people how to make pottery; he is also believed to have invented the potter's wheel. ${ }^{4}$

Ethnographic data: In 1503, soon after Columbus's discovery of America, an event happened that was to have long-lasting effects. On June 24 Captain Binot Paulmier de Gonneville's merchant ship set sail for Africa from Honfleur. However, the ship was blown off course and eventually found its way to the shores of Brazil. Captain Gonneville was a keen observer. He noticed that for their cooking the locals used wooden pots that were coated with clay about a finger thick to protect them from burning. Captain Gonneville's stories found their way into the Honfleur Chronicle to be discovered about 150 years later by Antoine-Yves Goguet, who made the assumption that potterymaking had initially involved coating wooden vessels with clay, until at some point people learned to make vessels of clay only. ${ }^{5}$ In later times this idea was advocated by many cultural historians, among whom we may mention LG Morgan, ${ }^{6}$ EB Taylor, ${ }^{7} \mathrm{JE} \mathrm{Lips}^{3}$ and others.
Their opinion was based on the facts that many tribes in Africa, South America and Melanesia used wicker vessels coated with clay inside and outside (Figure 1).

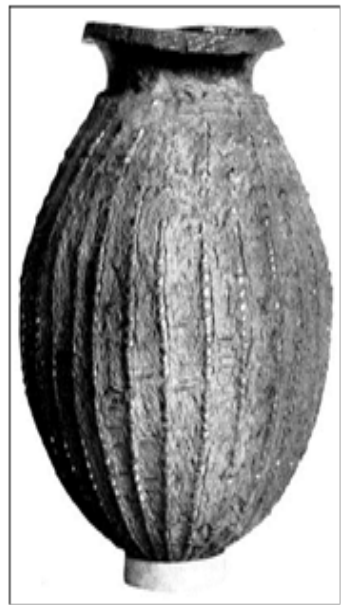

Figure I Wicker vessel coated with clay from Ruanda. ${ }^{24}$

Linguistic data: The hypothesis that pottery-making originated from coating wicker vessels with clay found support with linguists, who discovered that in some of the Indo-European languages the words for wicker fence, clay and clay vessel go back to the same stem. In his monograph on artisan terminology in the Slavic languages O.N. Trubachev wrote: "the main achievement in studies of prehistoric pottery-making is the thesis that pottery-making arose from wickerwork. Originally pottery-making was a version of wickerwork; the wall of ancient vessel is a kin to the wicker wall of an ancient dwelling". ${ }^{8}$

\section{Critique of the "basket" theory}

Some scholars noted that that was unlikely, since clay would shrink after drying and especially after firing and a vessel made over a wooden or wicker base would inevitably crack and break up. ${ }^{3}$ The History of Ceramics Laboratory, IA RAS, Moscow, has been investigating the issue for a number of years., ${ }^{3,-12}$ To check the "basket" theory we conducted experiments that involved coating firm wicker baskets with pure iron clay and clay mixed with animal manure. In both cases through wall cracks appeared in the coating after the vessels had dried. Sometime later IN Vassilyeva ${ }^{13}$ used four soft reed baskets, one of which was coated with silt on the inside, the second one with clay on the inside, the third one with clay on the outside and the fourth one with clay on both sides. As the vessels dried, surface cracks appeared (the largest ones on the fourth basket) and were plastered with the same coating as previously applied. After drying, the vessels were fired in a pit under a layer of dry dung for about two hours. The first and second baskets survived intact, had no cracks on either the inside or the outside and rang when tapped. The third basket was also intact but had both surface and through wall cracks, whereas the fourth one had completely deteriorated. The experiment has proven that, in principle, soft wicker containers could have been coated with silt or clay on the inside. ${ }^{13}$

The only question that at that point had no answer was whether ancient potters had indeed used wicker containers for making vessels. To answer that question we needed to find at least some traces of such baskets on ancient pottery. AA Bobrinsky and YB Tsetlin focused on 
Early Neolithic pottery from different archaeological cultures in the forest and steppe zones and primarily the earliest pottery from the Near East (Sotto and Hassuna cultures) and Far East (Osipovka culture). Our study involved shards from several hundred vessels, yet none of them has shown any traces of wickerwork on either the inner or the outer surface. The vessels from Tell Sotto in Iraq that show wicker imprints are made not of clay but of gypsum, ${ }^{14}$ which, however, does not shrink as it dries. Microscopy has revealed that the rough grooves on Early Neolithic vessels, instead of being traces of wicker, are the result of smoothing the vessel walls with special instruments. Thus, studies of the earliest pottery from different regions of the globe have not proven that the "basket" theory of the origins of pottery-making is correct. All of the above circumstances made us once again seek the answer to the question about the origins of pottery-making.

\section{Problem definition}

The question about the origin of pottery-making comprises two problems:

I. The origin of vessel shapes and

II. The origin of the manufacturing technology.

It is evident that any cultural phenomenon comes into being, on the one hand, as a response to the new requirements that people might have and, on the other hand, as a continuation of already existing cultural achievements. That is why in order to reconstruct the origin of pottery-making we need to understand, firstly, the possible prototypes of clay vessels and, secondly, the foundation on which pottery technologies will have developed. So, what is it that currently available data tells us about the origin of pottery-making?

\section{The origin of shapes of clay vessels}

The process should be considered in two aspects:

I. The containers that served as prototypes for different shapes of clay vessels

II. The functions of the earliest clay vessels.

\section{About the "prototypes" of clay vessels}

Before inventing clay vessels humans would have used other containers: stone, wooden, woven, calabashes, shells, etc., as known from ethnographic and archaeological data. Such containers can be divided into two groups:

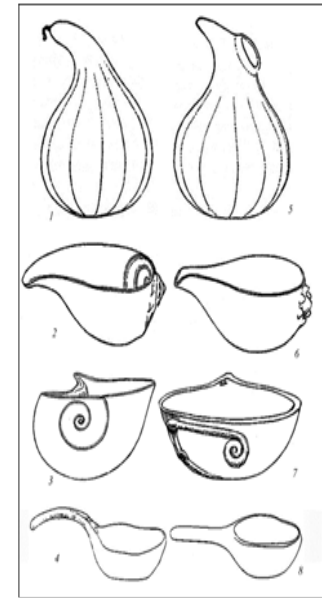

Figure 2 Natural containers made of a gourd (I), shells $(2,3)$, horn (4) and their clay copies $(5-8) .{ }^{25}$ a. Ready-to-use natural containers - calabashes, shells, horns, animal hides or stomachs (Figure 2)

b. Artificial ones - stone, bark, wooden or wicker (Figure 3).

Vessels made from organic materials, stone vessels from preNeolithic sites are well-known at Near Eastern sites that date to the 8th -7 th millennia BC..$^{15,16}$ The Early Neolithic clay vessels from the same region are also very simple in shape. ${ }^{14}$ Thus, the above facts indicate with a high degree of probability that the earliest clay vessels could have been created to imitate the already familiar natural or hand-made containers in a new material.

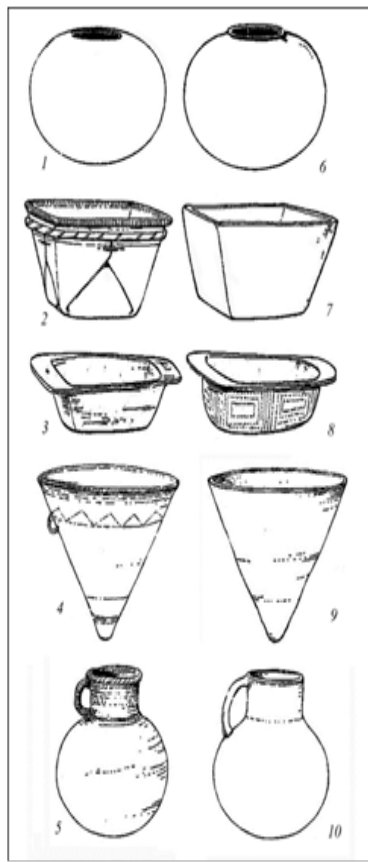

Figure 3 Artificial containers made of stone (I), bark (2), wooden (3), wicker $(4,5)$ and their clay copies $(6-10) .{ }^{25}$

\section{About the functions of the earliest clay vessels}

The present study uses information about the earliest vessels from sites in two geographically different regions: the Near East and Anatolia of 9-8 millennia ago, the Japan islands (Initial Jomon) and the Russian Far East (13-11 millennia ago). We have analyzed the data from 33 stone vessels, 16 stationary containers coated with clay or gypsum and 109 clay vessels from sites in the Near East and Anatolia. The stone (pre-Neolithic) vessels are small or very small (2.5 liters or less). As for general proportions, the vessels are mostly low and medium ones $(76 \%)$. The stationary vessels from pre-Neolithic times are of different sizes. About $30 \%$ are "mobile" vessels up to 50 liters. They could have been the earliest containers to be used for the same purposes as their latter clay counterparts. However, most of the stationary vessels (about 50\%) were quite large (200 to 800 liters). As to general proportions, $50 \%$ of the stationary vessels are low ones.

Almost all of the clay vessels are "mobile" ones (97\%). The majority (about 63\%) is small and very small (170 ml-2.5 liters). Medium-sized vessels amount to $24 \%$. It is logical that the volume of clay vessels is noticeably larger than that of the stone ones. However, their general proportions are practically the same. From the above facts we can make several conclusions: Firstly, the size of vessels depended on the material they were made of (stone vessels 
are noticeably smaller that the clay ones). Secondly, clay vessels evolved in two main directions: small mobile vessels (up to 2.51 ) or huge stationary ones (over 200 1); it is evident that the functional purpose of each of the types was different. Thirdly, the similarity in the general proportions of stone and mobile clay vessels points to a partial continuity in their function, even though clay vessels had, of course, a wider range of use.

The Japanese and Far Eastern vessels (69 items) that we have analyzed are all clay ones. All of the vessels are "mobile" ones (up to $50 l$ ) and in terms of volume can be divided into very small (14\%), small $(25 \%)$ and medium-sized (52\%). It is important to note that on the whole they are significantly larger that the mobile clay vessels from the Near East. As to general proportions, 94\% of these vessels are medium-sized ones. It is evident that the earliest Near Eastern vessels were functionally much more diverse than their Far Eastern counterparts. The earliest pottery from the Amur region has been used mostly for cooking. Summing up our study of the shapes of clay vessels we may conclude that the consistent patterns in their evolution were both of a general and of a local character. The general regularities are, firstly, that clay vessels would have most probably copied the shapes of natural and artificial non-clay containers, even though the clay vessels were more diverse; secondly, the general proportions of the earliest clay vessels were almost the same as those of still earlier non-clay ones, as well as those of other clay vessels from other regions. As to volume, the earliest clay vessels were in a kind of intermediary position between stone and stationary containers.

The local regularities are the regional differences in, firstly, the variety of vessels and, secondly, in their size. These differences had to do, on the one hand, with the variety of non-clay prototypes of the earliest clay vessels and, on the other hand, with the difference in their practical functions and use.

\section{The origin of pottery technology}

In this respect it is important to note that the traditions of working with clay as with natural plastic materials are much more ancient than pottery production as such. That is why by the time pottery-making appeared humans had already accumulated a rich experience in using clay-like materials for building their dwellings, hearths and ovens and for creating small sculptures for ritual purposes. At present we may consider it proven that the traditions of using different kinds of clay and clay-like materials, as well as the traditions of purposefully adding different artificial tempers to the pottery paste, go back to different human collectives which used to exist in different natural, climatic and economic conditions. To judge by the currently available data, Early Neolithic pottery was manufactured, firstly, from the natural materials at hand (clays or silts) without any artificial additives; secondly, from specially prepared pottery pastes with mineral tempers (broken rock, sand, grog, etc); thirdly, from specially prepared pottery pastes with organic tempers (animal and bird manure, etc).

\section{Variant one: making vessels from the natural materials at hand}

Such materials are, first of all, various silts (Figure 4), which in addition to clayey particles also have a lot of organic remains (mainly plants and broken mollusk shells) or mineral inclusions (mainly acute-angled or poorly-rounded natural sand). This tradition existed primarily in the forest and forest-steppe zone with temperate, subtropical and tropical climate, a lot of bogs and above-average humidity and also in piedmont areas. Examples of Early Neolithic silt pottery have been found in many different regions. ${ }^{17-19}$ In a humid climate, the vessels that were made of silts with a high content of natural organic materials or poorly-rounded natural sand needed at least some thermal influence in order to be functional. Mineral tempers increase the fire-resisting properties of a vessel, i.e. the capacity to endure the wide fluctuations of temperature that are inevitable in the fire-place. Such vessels require a long time firing process in reducing atmosphere (until $500^{\circ} \mathrm{C}$ ).

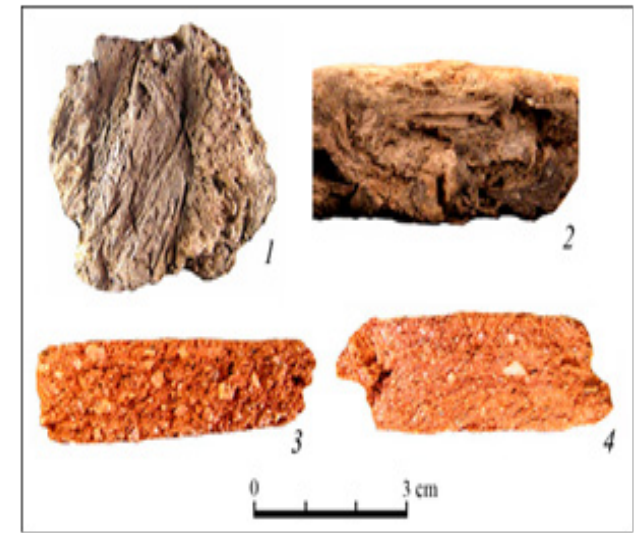

Figure 4 Sherds of ceramic vessels made of plain silt $(I, 2)$ and so-called mountain (upland) silt $(3,4)$.

Natural clays with a lot of natural mineral inclusions were another ready-to-use material. They can be found mainly in piedmont and mountain regions and usually contain composite acute-angled sand which can easily be mistaken for artificial temper of broken rock. In this case the vessels also require intentional firing under neither completely oxidizing nor completely reducing atmosphere (until 550$650^{\circ} \mathrm{C}$ ) in order to be usable for household purposes.

\section{Variant two: making vessels from a mixture of natural clay and artificial mineral tempers (Figure 5)}

In the Early Neolithic, pottery with artificial temper of sand or broken rock was fairly popular in various parts of the world. These traditions probably go back to the tradition of making vessels from natural clay rich in natural mineral tempers. The potters who moved from piedmont and mountain regions to flat country, where such clay were rare, had to create their own pottery pastes by adding mineral tempers to re-create the natural clay there were familiar with. Such vessels also required the same intentional firing with a temperature after $650-700^{\circ} \mathrm{C}$

Until recently we had no clear understanding why potters used to add grog, i.e. crushed ceramics, to the pottery paste. In literature we can come across the opinion that potters used grog so that the new vessels may be as strong as the old ones, or in order to stress the continuity between generations of potters. ${ }^{20}$ If that opinion is correct, grog was used for ritual purposes and not for practical ones.

However, some recent observations allow bringing forth another assumption. Studies of the earliest Osipovka culture pottery (13 000 11000 years ago) from the Far East of Russia have revealed that the potters used a silt paste with natural inclusions of shale and ironstone. In some of the cases their content in the pottery paste amounted to $30-50 \%$ of the overall volume. Both shale and ironstone particles look like grog temper. As to their qualities, these inclusions improve pottery paste the same way that artificial mineral temper does, i.e. they 
increase the fireproof properties of the vessels. Pottery of the more recent Mariinskaya culture was made of clay with grog temper, which may possibly be interpreted as a conscious imitation of the more ancient Osipovka culture tradition. The above facts allow assuming that when the potters began to work with the new clays that had no shale or ironstone inclusions they artificially recreated the familiar composition of the pottery paste through adding grog. In this case the first essays in using grog temper reflect the same trend as in the case of sand and broken rock tempers, which became artificial imitations of earlier natural materials.

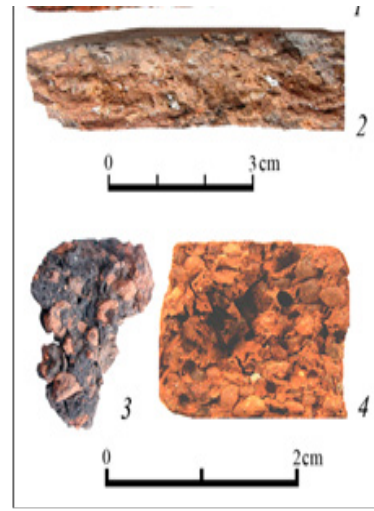

Figure 5 Sherds of vessels made pottery pastes with sand (4), broken rock (I) and grog $(2,3)$ temper.

\section{Variant three: making vessels from a mixture of clay and artificial organic materials (Figure 6)}

To judge by the currently available data, waterfowl manure and dung were the most popular tempers in this case. Waterfowl manure in the pottery paste of Early Neolithic vessels was a specific feature of the communities that subsisted on hunting, fishing and gathering, whereas dung was used exclusively by the communities that were engaged in farming and animal husbandry. ${ }^{21,22}$ This is connected with the fact that the latter used for their vessels the dung of domestic animals. Humans had begun to use that material long before potterymaking was invented and adobe buildings of sun-dried blocks or bricks dating back to pre-Neolithic times can be found in many places in regions with a hot and dry climate.

Waterfowl manure, in the Early Neolithic was easily obtainable at bird rookeries; travelers to the mid-Volga mentioned the vast rookeries they saw there in as late as the 19th century. It is quite possible that in antiquity such rookeries could be found almost in all moderateclimate water basins in the spring and autumn seasons. Adding large amounts of bird manure to the pottery paste increased its plasticity, caused strong self-cementation of the clay particles and reduced shrinkage during drying and firing. Such vessels could only take long firing at low temperatures or short-term firing at temperatures of red heat $\left(\right.$ over $\left.650^{\circ} \mathrm{C}\right)$. Longer and more intensive firing burned out all the organic materials and the vessels usually became too porous and bad for domestic use. Archaeological data shows that the bird manure for the pottery paste could be either fresh or dried and crushed. It is quite probable that at first potters started using fresh manure, since the positive properties of this temper are more effective in the fresh state. Ancient potters must have started using bird manure as a temper when they changed from using plain silts, which were rich in organic plant matter, to artificial pastes that combined bird manure and clay. Since plain silt was rich in waterfowl manure from birds nesting in the shallows and the riverside, the pastes that combined clay and bird manure could have imitated the ready-to-use natural material from earlier times.

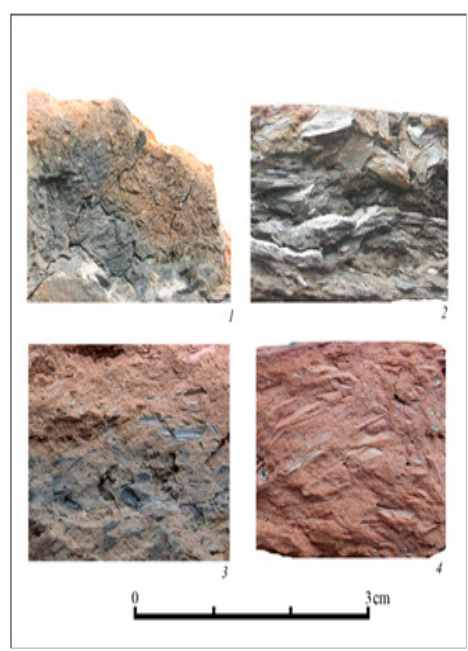

Figure 6 Sherds of vessels made of pottery pastes with waterfowl manure $(I)$, broken shell $(2)$ and dung $(3,4)$ temper.

Animal dung, this material, even though formally similar to the one described previously, was used for quite different practical purposes. I have already mentioned that, starting from very ancient times, animal dung mixed with clay was used in building houses. It must have been at that time that people noticed the important qualities of this material which was stronger and more waterproof than pure clay. This quality was especially evident in the rainy seasons. Initially people must have obtained this mixture of clay and dung from where it occurred naturally, that is, from pastures, corrals and wateringplaces. The abundance of natural clays and the very thin soil layer in many areas of the near and Middle East were another reason why this mixture was easily available. The dung must have mixed with the clay mainly during the rainy season after large groups of animals had trampled the ground in a limited space. In later times potters started to use dung temper in pottery paste in order to purposefully imitate the previously available natural mixture. Studies of Sotto and Hassuna pottery show that the potters often used quite large amounts of manure of both great and small cattle for the pottery paste. ${ }^{21,23}$ The pottery was briefly fired at high temperatures, as seen from the three layers on the fractures which show a sharp contrast in color between the middle and outer layers of the shards.

\section{Conclusion}

Firstly, ancient pottery-making was an integral part of the overall evolution of human culture and many of the traditions that further on evolved in close connection with other areas of human culture, from which it borrowed many of the traditions which later became part of the evolution of pottery-making itself. Secondly, the discovery of potterymaking was a polycentric process which began in many regions of the Earth to eventually become a worldwide phenomenon the origins of which we cannot locate precisely. Even though the different "source areas" of pottery-making were independent of each other, the process of its development had nonetheless one consistent pattern: potters had 
initially made their vessels from ready-to-use natural materials. When at some point those were no longer available, potters tried to re-create them through adding certain mineral or organic tempers to the pottery paste. The tempers, on the one hand, made the pottery paste look like the natural materials the potters had once used and, on the other hand, helped recreate their physical and technical qualities. ${ }^{24,25}$

\section{Acknowledgements}

I would like to tell many thanks to my collaegues - Dr. Helena Volkova (Moscow), Dr Natalia Salugina and Dr Irina Vasilieva (Samara), Dr Alex Gibson (Breadford University), Dr Michela Spataro (British Museum) and Tatiana Borichava, who prepared an English version of the paper.

\section{Conflict of interest}

Author declares that there is no conflict of interest.

\section{References}

1. King James Version. The Holy Bible. ABS: New York.

2. Fraser JG. Folk-lore in the Old Testament. Studies in Comparative Religion, Legend, and Law. Vol 1. Macmillan and Co., London; 1918. 570 p.

3. Lips JE. The Origin of Things. Cultural History of Man. London: Harrap. 1949. 420 p.

4. Bobrinsky AA. The Origin of Pottery Production. Ukraine's Pottery Production Vol 1. Kiev: Ukraine; 1993. p. 39-55.

5. Goguet AY. The Origin of Laws, Arts and Sciences; and Their Progress among the Most Ancient Nations. Edinburgh: George Robinson; 1775, $402 \mathrm{p}$.

6. Morgan LG. Ancient Society of Researches in the Lines of Human Progress from Savagery through Barbarism to Civilization. Calcutta; 1944. $569 \mathrm{p}$.

7. Taylor EB. Researches into the Early History of Mankind and the Development of Civilization. London; 1865. 378 p.

8. Trubachev ON. Handicraft terminology in Slavic languages. Moscow: Nauka; 1966. 416 p.

9. Bobrinsky AA. On the structure and origin of pottery technology. Моnuments, Concept, Discoveries, Versions. Vol. 1. St.Peterburg Pskov: IHMC RAS; 1997. p. 90-96.

10. Bobrinsky AA. Technological Data about the Origin of Pottery Production. Problems of the Volga-region archaeology Vol 4. Samara: Science and Technology Center; 2006. p. 413-421.
11. Tsetlin YB. Recent Notions on the Origin of Pottery Production. Journal of History. 2013;3(23):74-80.

12. Tsetlin YB. Forming of Ancient Pottery Production: mechanisms and results. Proceedings of the IV $(X X)$ All-Russia archeological congress in Kazan. Vol I. Kazan: Otechestvo; 2014. p. 370-373.

13. Vasilyeva IN. On the Problem of the Origin of Pottery Production in the Volga Region. Problems of the Volga-region archaeology. Vol 4. Samara: Science and Technology Center; 2006. 426-439.

14. Bader NO. Earliest Cultivators in Northern Mesopotamia. Moscow: Nauka; 1989. $368 \mathrm{p}$

15. Mellaart J. The Neolithic of the Near East. London: Thames \& Hudson; 1975. $300 \mathrm{p}$.

16. Rosenberg M, Davis MK. Hallan Cemi Tepesi, an early aceramic Neolithic site in Eastern Anatolia: Some preliminary observations concerning material culture. Anatolia; 1992. p. 1-18.

17. Bobrinsky AA, Vasilyev IN. Plastic Raw Materials in Neolithic Pottery Production. Documenta Prehistorica. 2012;39:67-74.

18. Bobrinsky AA. Pottery Technology as the Subject of Historical and Cultural Study. Actual Problems of Ancient Pottery Production Study (collective monograph). Samara: Samara State Pedagogical Univ; 1999. p. 5-109.

19. Tsetlin YB. On the Origin of the Upper Volga Culture. The Influence of the Environment on the Development of Ancient Societies (Proceedings of the IV $V^{\text {th }}$ Halikov conference). Yoshkar-Ola: MarNII; 2007. p. 197-208.

20. Iordansky VB. Beasts, people, gods. Essays on African mythology. Moscow: Nauka; 1991. 319 p.

21. Tsetlin YB. Organic temper in ancient ceramics: Ceramic in the Society. Proceedings of the 6th European Meeting on Ancient Ceramics. Fribourg: Switzerland; 2003. p. 289-310.

22. Tsetlin YB. Ancient Pottery Traditions in Tribes with Hunting-and-Gathering and Productive Economy. The Old Potter's Almanack. 2003;8(2):4-6.

23. Bobrinsky AA. Technological description of the ceramics from Tell Sotto and Kul Tepe. In: Bader NO, editor. Earliest Cultivators in Northern Mesopotamia. Moscow: Nauka; 1989. p. 327-334.

24. Rieth A. 5000 Jahre Topferscheibe. Jan Thorbecke Verlag Konstanz. 1978.

25. Holmes WH. Origin and Development of Form and Ornament in Ceramic Art. Fourth Annual Report of the Bureau of Ethnology. Smithsonian Institution. Government Printing Office: Washington; 1886. p. 437-465. 